\title{
Desain Simulasi Sistem Pengaturan Kecepatan Motor Induksi Tiga Fasa dengan Switching Space Vector Pulse Width Modulation
}

\author{
Muhamad Yusuf ${ }^{1}$, Vicky Prasetia $^{2}$, Sugeng Dwi Riyanto ${ }^{3}$, Arif Ainur Rafiq ${ }^{4}$ \\ 1,2,3,4 Program Studi Teknik Elektronika, Politeknik Negeri Cilacap \\ Email : yusuf@politeknikcilacap.ac.id ${ }^{1)}$ \\ vickyprasetia@politeknikcilacap.ac.id ${ }^{2}$ \\ sugeng@politeknikcilacap.ac.id ${ }^{3)}$ \\ arifainurrafiq@politeknikcilacap.ac.id ${ }^{4}$
}

\begin{abstract}
Induction motor has been used by industry as a source of mechanical energy. Induction motors are very reliable, inexpensive, and easy to maintain. Induction motor is difficult to control because one of the nonlinear plant categories. The method can be used to regulate the speed of an induction motor is to set the vector. In order for an induction motor to be easily controlled like a separate dc booster motor, the induction motor is modeled in the rotary axis reference (d-q model). This research applies an induction motor speed regulation scheme using Switching Space Vector Pulse Width Modulation (SVPWM). This system produces a steady state error averaging below 4 (four) rpm or equal to $0.3 \%$ with a load torque of between $5 \mathrm{Nm}$ to $35 \mathrm{Nm}$.
\end{abstract}

Keywords : d-q model, SVPWM, Three phase induction motor

\section{INTISARI}

Motor induksi telah dimanfaatkan industri sebagai sumber energi mekanik. Motor induksi sangat handal, murah, dan mudah dalam perawatannya. Motor induksi sulit dikendalikan karena salah satu kategori plant nonlinier. Salah satu cara yang digunakan untuk mengatur kecepatan motor induksi adalah mengatur vektornya. Agar motor induksi mudah untuk dikendalikan seperti motor dc penguat terpisah, maka motor induksi dimodelkan dalam referensi sumbu putar (model d-q). Penelitian ini menerapkan skema pengaturan kecepatan motor induksi menggunakan Switching Space Vector Pulse Width Modulation (SVPWM). Sistem ini menghasilkan error steady state rata-rata di bawah 4 (empat) rpm atau sebesar 0,3\% dengan diberi torsi beban antara $5 \mathrm{Nm}$ sampai $35 \mathrm{Nm}$.

Kata kunci: Model d-q, Motor Induksi Tiga Fasa, SVPWM

\section{PENDAHULUAN}

Sejak bergulirnya revolusi industri ke-3, banyak peralatan industri digantikan dengan mesin. Saat ini mesinmesin listrik banyak beroperasi menggantikan tugas dari manusia. Salah satu mesin listrik yang banyak dipakai adalah motor induksi. Motor induksi merupakan salah satu mesin listrik yang paling banyak digunakan dalam dunia industri. Motor jenis ini banyak diaplikasikan dalam bidang HVAC (Heating, Ventilation dan Air-Conditioning), Industrial drives (motion control, Robotic), Automotive (Electric Vehicle) dll. Motor jenis ini memiliki beberapa kelebihan diantaranya konstruksinya sederhana dan kokoh, harganya relatif murah, serta perawatannya mudah. Pengaturan motor induksi lebih sulit bila dibandingkan dengan motor arus searah/dc, karena fluks dan torsi yang dihasilkan oleh motor induksi saling berkaitan atau tidak bebas. Metode pengaturan vektor adalah pengaturan melalui pemisahan (decoupling) variabel stator dari motor induksi, sehingga seperti motor arus searah atau motor dc penguat terpisah. Banyak penelitian tentang pengaturan kecepatan motor induksi berbasis pengaturan vektor yang pernah dilakukan oleh [3], [4], [6], [7], [8] untuk menyederhanakan struktur pengaturan kecepatan motor induksi yang digunakan sebagai penggerak elektrik dengan menggunakan transformasi koordinat model d-q.

Pengaturan kecepatan motor induksi tiga fasa umumnya menggunakan inverter tiga fasa. Masukkan inverter adalah tegangan dc kemudian diubah menjadi tegangan ac dengan melakukan switching pada tegangan DC. Banyak berkembang metode switching pada inverter salah satunya adalah SVPWM. Metode PWM ini berdasar adanya vektor ruang pada koordinat abc (tiga fasa). SVPWM ini adalah sebuah teknik tingkat lanjut untuk membangkitkan gelombang sinus yang menghasilkan bentuk tegangan yang lebih baik untuk motor induksi dan total distorsi harmonik yang rendah. Torsi beban yang berubah menyebabkan kecepatan motor juga berubah. Penelitian ini merancang sebuah pengaturan motor induksi tiga fasa dengan switching SVPWM menggunakan fuzzy PI kontroler. Penambahan 
fuzzy diharapkan nilai parameter kontroler juga berubah agar didapat error steady state di bawah 10rpm.

\section{LANDASAN TEORI}

Pada bagian ini dibahas mengenai model matematis motor induksi dalam model $\mathrm{d}-\mathrm{q}$ dan metode switching SVPWM.

\section{A. Motor Induksi Tiga Fasa}

Salah satu jenis motor induksi tiga fasa adalah tipe squirrel cage yang mempunyai beberapa kelebihan jika dibandingkan dengan motor DC. Beberapa kelebihannya adalah perawatannya mudah, lebih handal, harganya relatif murah, dan memiliki efisiensi yang tinggi. Motor jenis ini banyak dioperasikan pada kecepatan dan beban konstan [2].

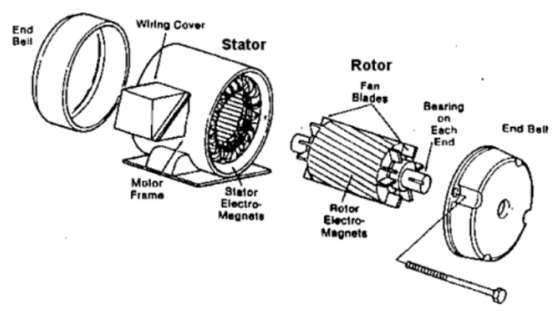

Gambar 1. Konstruksi motor induksi tiga fasa

Motor induksi terdiri dari rangkaian stator (bagian yang tetap), rangkaian rotor (bagian yang bergerak), bearing mekanik dan celah udara yang ditunjukkan pada Gambar 1.

\section{B. Rangkaian Ekivalen Motor Induksi}

Analisis motor induksi dimulai dengan menggunakan rangkaian ekivalen seperti pada Gambar 2. Pada gambar tersebut, keadaan motor induksi dapat dianggap sebagai transformator dimana stator merupakan rangkaian primer dan rotor sebagai rangkaian sekunder. Diasumsikan tegangan sumber adalah sinusoidal dan dalam keadaan tunak. Pada kenyataanya ditemui permasalahan tegangan sumber yang tidak sinusoidal dan ada perubahan beban. Oleh karena itu, dibutuhkan pemodelan lain dari motor induksi sehingga analisis terhadap motor induksi dapat dilakukan lebih mudah dan fleksibel.

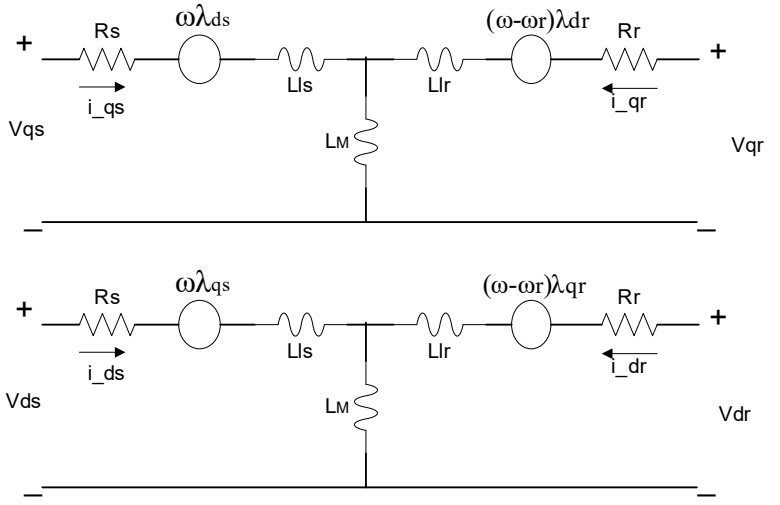

Gambar 2. Rangkaian ekivalen dq motor induksi 3 fasa [2]

Dalam hal ini, model yang digunakan adalah model motor induksi dalam koordinat $\mathrm{d}$-q. Diperlukan suatu transformasi koordinat motor induksi dari koordinat tiga fasa (koordinat abc) menjadi koordinat dua fasa (koordinat $\mathrm{d}-\mathrm{q}$ ) dengan mengikuti Persamaan (1).

$$
\begin{aligned}
& V_{q s}=R_{s} \cdot i_{q s}+\omega \cdot \lambda_{d s}+\frac{d}{d t} \cdot \lambda_{q s} \\
& V_{d s}=R_{s} \cdot i_{d s}+\omega \cdot \lambda_{q s}+\frac{d}{d t} \cdot \lambda_{d s} \\
& V_{q r}=R_{s} \cdot i_{q r}+\left(\omega-\omega_{r}\right) \omega \cdot \lambda_{d r}+\frac{d}{d t} \cdot \lambda_{q r} \\
& V_{d r}=R_{s} \cdot i_{d r}+\left(\omega-\omega_{r}\right) \omega \cdot \lambda_{q r}+\frac{d}{d t} \cdot \lambda_{d r}
\end{aligned}
$$

Keunggulan dari model motor induksi koordinat $d-q$ selain mempermudah analisis adalah juga agar motor induksi tiga fasa memiliki sifat atau perilaku yang menyerupai motor DC sehingga lebih mudah dikontrol. Analisis tersebut meliputi tegangan stator dan tegangan rotor, fluks stator dan fluks rotor, serta torsi elektromagnetik dari motor induksi. Berdasarkan Gambar 2, persamaan tegangan stator dan rotor motor induksi merupakan fungsi arus stator dan arus rotor, serta fungsi fluks yang tercakup pada kumparan dinyatakan dengan persamaan (2).

$$
\begin{aligned}
& \lambda_{q s}=L_{l s} \cdot i_{q s}+M .\left(i_{q s}+i_{q r}\right) \\
& \lambda_{d s}=L_{l s} \cdot i_{d s}+M .\left(i_{d s}+i_{d r}\right) \\
& \lambda_{q r}=L_{l r} \cdot i_{q r}+M .\left(i_{q s}+i_{q r}\right) \\
& \lambda_{d r}=L_{l r} \cdot i_{d r}+M .\left(i_{d s}+i_{d r}\right)
\end{aligned}
$$


Persamaan (1) dan (2) dapat dinyatakan dalam persamaan matriks dengan melakukan subtitusi hasilnya seperti pada Persamaan (3)

$$
\left[\begin{array}{c}
V_{q s} \\
V_{d s} \\
V_{q r} \\
V_{d r}
\end{array}\right]=\left[\begin{array}{cccc}
R_{s}+p L_{s} & \omega L_{s} & p M & \omega M \\
-\omega L_{s} & R_{s}+p L_{s} & -\omega M & p M \\
p M & \left(\omega-\omega_{r}\right) M & R_{r}+p L_{r} & \left(\omega-\omega_{r}\right) L_{r} \\
-\left(\omega-\omega_{r}\right) M & p M & -\left(\omega-\omega_{r}\right) L_{r} & R_{r}+p L_{r}
\end{array}\right] \cdot\left[\begin{array}{c}
i_{q s} \\
i_{d s} \\
i_{q r} \\
i_{d r}
\end{array}\right]
$$

dengan,

$$
L_{s}=L_{l s}+M
$$

Persamaan model matematis motor induksi tiga fasa jika dibuat dalam bentuk state space ditunjukkan pada Persamaan (4) sampai (6). Diferensial arus stator dan rotor pada sumbu koordinat d (direct axis) ditunjukkan pada Persamaan (4).

$$
\begin{gathered}
\frac{d}{d t}\left[\begin{array}{l}
i_{d s} \\
i_{d r}
\end{array}\right]=\frac{1}{D}\left[\begin{array}{cccc}
-R_{s} L_{r} & \omega_{r} M^{2} & R_{r} M & \omega_{r} L_{r} M \\
R_{s} M & -\omega_{r} L_{s} M^{2} & -R_{s} L_{s} & \omega_{r} L_{r} L_{s}
\end{array}\right]\left[\begin{array}{c}
i_{d s} \\
i_{q s} \\
i_{d r} \\
i_{q r}
\end{array}\right] \\
+\frac{1}{D}\left[\begin{array}{cccc}
L_{r} & 0 & -M & 0 \\
-M & 0 & L_{s} & 0
\end{array}\right] \cdot\left[\begin{array}{c}
V_{d s} \\
V_{q s} \\
V_{d r} \\
V_{q r}
\end{array}\right] \\
D=L_{s} L_{r}-M^{2}
\end{gathered}
$$

Sedangkan diferensial arus stator dan rotor pada sumbu koordinat q (quadratur axis) ditunjukkan pada Persamaan (5).

$$
\begin{aligned}
\frac{d}{d t}\left[\begin{array}{c}
i_{d s} \\
i_{q s} \\
i_{d r} \\
i_{q r}
\end{array}\right]= & \frac{1}{D}\left[\begin{array}{cccc}
-R_{s} L_{r} & \omega_{r} M^{2} & R_{r} M & \omega_{r} L_{r} M \\
R_{s} M & -\omega_{r} L_{s} M^{2} & -R_{s} L_{s} & \omega_{r} L_{r} L_{s} \\
-\omega_{r} M^{2} & R_{s} L_{r} & \omega_{r} L_{r} M & R_{r} M \\
\omega_{r} L_{s} M & R_{s} M & \omega_{r} L_{r} L_{s} & -R_{r} L_{s}
\end{array}\right] \times\left[\begin{array}{c}
i_{d s} \\
i_{q s} \\
i_{d r} \\
i_{q r}
\end{array}\right] \\
+ & \frac{1}{D}\left[\begin{array}{cccc}
L_{r} & 0 & -M & 0 \\
-M & 0 & L_{r} & 0 \\
0 & L_{r} & 0 & -M \\
0 & M & 0 & L_{s}
\end{array}\right] \times\left[\begin{array}{c}
V_{d s} \\
V_{q s} \\
V_{d r} \\
V_{q r}
\end{array}\right]
\end{aligned}
$$

Jika pada sumbu d dan q digabungkan akan menjadi diferensial arus motor pada sumbu d-q (direct-quadratur axis) dengan menggabungkan persamaan (4) dan (5) maka bentuk state space model motor induksi menjadi persamaan (6).

$$
\begin{aligned}
& \frac{d}{d t}\left[\begin{array}{c}
i_{d s} \\
i_{q s} \\
i_{d r} \\
i_{q r}
\end{array}\right]=\frac{1}{D}\left[\begin{array}{cccc}
-R_{s} L_{r} & \omega_{r} M^{2} & R_{r} M & \omega_{r} L_{r} M \\
R_{s} M & -\omega_{r} L_{s} M^{2} & -R_{s} L_{s} & \omega_{r} L_{r} L_{s} \\
-\omega_{r} M^{2} & R_{s} L_{r} & \omega_{r} L_{r} M & R_{r} M \\
\omega_{r} L_{s} M & R_{s} M & \omega_{r} L_{r} L_{s} & -R_{r} L_{s}
\end{array}\right] \\
& \times\left[\begin{array}{c}
i_{d s} \\
i_{q s} \\
i_{d r} \\
i_{q r}
\end{array}\right]+\frac{1}{D}\left[\begin{array}{cccc}
L_{r} & 0 & -M & 0 \\
-M & 0 & L_{r} & 0 \\
0 & L_{r} & 0 & -M \\
0 & M & 0 & L_{s}
\end{array}\right] \times\left[\begin{array}{c}
V_{d s} \\
V_{q s} \\
0 \\
0
\end{array}\right]
\end{aligned}
$$

Persamaan torsi yang dihasilkan oleh motor dinyatakan sebagai jumlah dari daya dibandingkan dengan kecepatan mekanik. Nilai torsi motor induksi dapat dinyatakan dalam Persamaan (7).

$$
T_{e}=\frac{3}{2} \frac{p}{\omega_{r}}\left[\omega\left(\lambda_{d s} \cdot i_{q s}-\lambda_{q s} \cdot i_{d s}\right)+\left(\omega-\omega_{r}\right)\left(\lambda_{d r} \cdot i_{q r}-\lambda_{q r} \cdot i_{d r}\right)\right]
$$

Hubungan torsi dengan fluks dapat dinyatakan dalam Persamaan (8).

$$
\begin{aligned}
\lambda_{d s} i_{q s}-\lambda_{q s} \cdot i_{d s} & =-\left(\lambda_{d r} \cdot i_{q r}-\lambda_{q r} \cdot i_{d r}\right) \\
& =L_{M}\left(i_{d r} \cdot i_{q s}-i_{q r} \cdot i_{d s}\right)
\end{aligned}
$$

Sehingga persamaan torsinya dapat dirumuskan pada Persamaan (9) sebagai berikut:

$$
\begin{aligned}
T_{e} & =\frac{3}{2} p \cdot L_{M}\left(i_{d r} \cdot i_{q s}-i_{q r} \cdot i_{d s}\right) \\
T_{e} & =\frac{3}{2} p\left(\lambda_{q r} \cdot i_{d r}-\lambda_{d r} \cdot i_{q r}\right) \\
T_{e} & =\frac{3}{2} p\left(\lambda_{d s} i_{q s}-\lambda_{q s} i_{d s}\right)
\end{aligned}
$$

Kecepatan putaran motor induksi merupakan fungsi dari torsi elektromagnetik dan torsi beban. Adapun rumusan untuk mendapatkan kecepatan motor induksi ditunjukkan pada Persamaan (10) dan (11).

$$
\begin{aligned}
& \frac{J}{p} \frac{d}{d t} \omega_{r}+B . \omega_{r}=T_{e}-T_{L} \\
& \frac{d}{d t} \theta_{r}=\omega_{r}
\end{aligned}
$$

dimana,

$\mathrm{T}_{\mathrm{L}} \quad$ : torsi beban (N.m)

$\mathrm{T}_{\mathrm{e}} \quad$ : torsi elektromagnetik (N.m)

B : konstanta gesek motor $\left(\mathrm{kg} \cdot \mathrm{m}^{2} / \mathrm{s}\right)$

J : momen inersia $\left(\mathrm{kg} . \mathrm{m}^{2}\right)$

$\mathrm{p} \quad$ : jumlah pasang kutub 
$\omega_{\mathrm{r}} \quad:$ kecepatan angular rotor (rad/detik)

$\theta_{\mathrm{r}} \quad$ : posisi sudut (rad)

$V_{q s}, V_{d s}$ : tegangan stator pada sumbu dq (Volt)

$V_{q r}, V_{d r}$ : tegangan rotor pada sumbu dq (Volt)

$i_{q s}, i_{d s}$ : arus stator pada sumbu dq (Ampere)

$i_{q r}, i_{d r}:$ arus rotor pada sumbu dq (Ampere)

$\lambda_{q s}, \lambda_{d s}$ : fluks stator pada sumbu dq (Webber)

$\lambda_{q r}, \lambda_{d r}$ : fluks rotor pada sumbu dq (Webber)

$R_{s} \quad$ : tahanan stator

$R_{r} \quad$ : tahanan rotor

$L_{l s} \quad$ : induktansi diri stator

(Henry)

$L_{l r} \quad$ : induktansi diri rotor

(Henry)

$M \quad$ : induktansi mutual

(Henry)

\section{Switching SVPWM}

Space Vector Modulation (SVM) awalnya dikembangkan sebagai pendekatan vektor pada Pulse Width Modulation (PWM) untuk Inverter tiga fasa. Metode PWM ini didasarkan pada adanya vektor ruang pada koordinat abc (tiga fasa). SVPWM adalah sebuah pendekatan yang berbeda dengan Modulasi PWM, yang mana ini berdasarkan pada vektor ruang dari tegangan dalam bidang $\alpha-\beta$. Komponen $\alpha-\beta$ dicari dengan transformasi clarke. SVPWM mengacu pada urutan pensaklaran yang khusus dari enam transistor power yang menghasilkan distorsi harmonik dalam tegangan output dan arus yang lebih efisien.

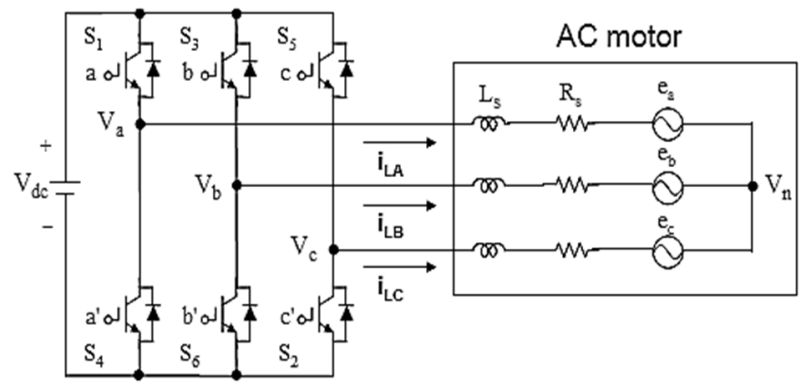

Gambar 3. Skema inverter tiga fasa

Model rangkaian dari Inverter SVPWM sumber tegangan tiga fasa secara umum ditunjukkan pada Gambar 3. $\mathrm{S}_{1}$ sampai $\mathrm{S}_{6}$ adalah 6 (enam) saklarsaklar power yang membentuk output, yang dikendalikan oleh perubahan pensaklaran a, a', b, b' dan c, c' dalam hal ini saklar power dapat menggunakan mosfet atau IGBT. Ketika saklar atas "ON" atau a, b dan c adalah "1", maka saklar bawah yang berhubungan adalah "OFF" atau a', b' dan c' adalah " 0 ". Oleh karena itu variabel switching a,b,c dengan a',b',c' akan menghasilkan delapan kemungkinan seperti yang terlihat pada Tabel 1. Delapan kemungkinan menghasilkan delapan buah vektor tegangan yang terdiri dari V0 sampai dengan V7. Untuk menjalankan SVPWM, persamaan tegangan pada kerangka acuan abc harus diubah menjadi kerangka acuan $\alpha \beta$ yang terdiri dari sumbu horizontal $\alpha$ dan sumbu vertikal $\beta$.

Tabel 1. Nilai tegangan tiap vektor tegangan

\begin{tabular}{|c|c|c|c|c|c|c|c|c|c|}
\hline \multirow{2}{*}{$\begin{array}{c}\text { Voltage } \\
\text { Vectors }\end{array}$} & \multicolumn{3}{|c|}{ Switching Vectors } & \multicolumn{2}{|c|}{ Line to neutral voltage } & \multicolumn{3}{|c|}{ Line to line voltage } \\
\cline { 2 - 11 } & $\mathrm{a}$ & $\mathrm{b}$ & $\mathrm{c}$ & $\mathrm{V}_{\mathrm{an}}$ & $\mathrm{V}_{\mathrm{bn}}$ & $\mathrm{V}_{\mathrm{cn}}$ & $\mathrm{V}_{\mathrm{ab}}$ & $\mathrm{V}_{\mathrm{bc}}$ & $\mathrm{V}_{\mathrm{ca}}$ \\
\hline $\mathrm{V}_{0}$ & 0 & 0 & 0 & 0 & 0 & 0 & 0 & 0 & 0 \\
\hline $\mathrm{V}_{1}$ & 1 & 0 & 0 & $2 / 3$ & $-1 / 3$ & $-1 / 3$ & 1 & 0 & -1 \\
\hline $\mathrm{V}_{2}$ & 1 & 1 & 0 & $1 / 3$ & $1 / 3$ & $-2 / 3$ & 0 & 1 & -1 \\
\hline $\mathrm{V}_{3}$ & 0 & 1 & 0 & $-1 / 3$ & $2 / 3$ & $-1 / 3$ & -1 & 1 & 0 \\
\hline $\mathrm{V}_{4}$ & 0 & 1 & 1 & $-2 / 3$ & $1 / 3$ & $1 / 3$ & -1 & 0 & 1 \\
\hline $\mathrm{V}_{5}$ & 0 & 0 & 1 & $-1 / 3$ & $-1 / 3$ & $2 / 3$ & 0 & -1 & 1 \\
\hline $\mathrm{V}_{6}$ & 1 & 0 & 1 & $1 / 3$ & $-2 / 3$ & $1 / 3$ & 1 & -1 & 0 \\
\hline $\mathrm{V}_{7}$ & 1 & 1 & 1 & 0 & 0 & 0 & 0 & 0 & 0 \\
\hline
\end{tabular}

Enam buah vektor aktif tersebut dapat dipetakan dalam bentuk hexagonal dengan beda sudut 60 derajat seperti terlihat pada Gambar 4.

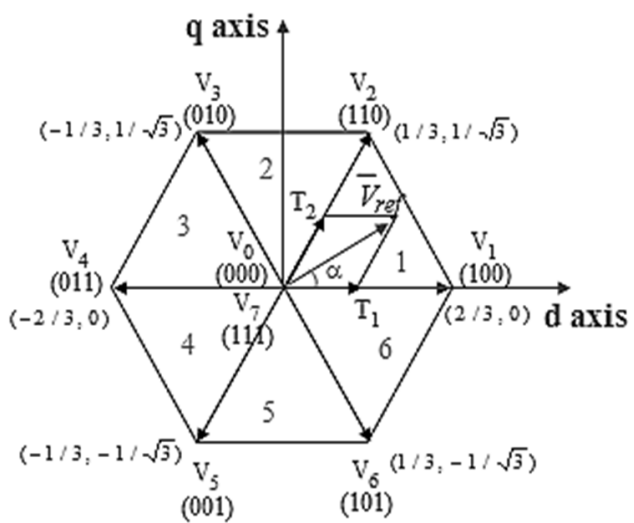

Gambar 4. Dasar pensaklaran vektor dan sektor

Tujuan dari teknik SVM adalah berusaha mendekati vektor tegangan referensi $\left(V_{\text {ref }}\right)$ menggunakan 8 pola pensaklaran di atas. Salah satu caranya adalah dengan menghasilkan tegangan keluaran rata-rata dari inverter pada selang waktu $T$ yang akan sama hasilnya dengan besar $V_{\text {ref }}$ pada selang waktu yang sama juga. Prinsip kerja dari SVM adalah menghasilkan tegangan sinusoida dengan amplitudo konstan dan 
Jurnal ECOTIPE, Volume 6, No.1, April 2019, Hal. 24-31

p-ISSN 2355-5068, e-ISSN 2622-4852

DOI: $10.33019 /$ ecotipe.v6i1.943

frekuensi pensaklaran yang konstan dari vektor yang berputar. Teknik ini menghasilkan tegangan keluaran yang besarnya tepat dengan tegangan referensinya melalui kombinasi dari 8 bentuk pensaklaran $\left(\mathrm{V}_{0}-\mathrm{V}_{7}\right)$. Hubungan antara vektor perubahan switching $[\mathrm{a}, \mathrm{b}, \mathrm{c}]^{\mathrm{t}}$ dan tegangan vektor line $\mathrm{ke}$ line $\left[\begin{array}{lll}\mathrm{V}_{\mathrm{ab}} & \mathrm{V}_{\mathrm{bc}} & \mathrm{V}_{\mathrm{ca}}\end{array}\right]^{\mathrm{t}}$ ditunjukkan pada Persamaan (12).

$$
\left[\begin{array}{l}
V_{a b} \\
V_{b c} \\
V_{c a}
\end{array}\right]=V_{d c}\left[\begin{array}{ccc}
1 & -1 & 0 \\
0 & 1 & -1 \\
-1 & 0 & 1
\end{array}\right] \cdot\left[\begin{array}{l}
\mathrm{a} \\
\mathbf{b} \\
\mathbf{c}
\end{array}\right]
$$

Untuk mendapatkan nilai besarnya tegangan fasa terhadap sumbu netral $\left[\mathrm{V}_{\mathrm{an}} \mathrm{V}_{\mathrm{bn}} \mathrm{V}_{\mathrm{cn}}\right]^{\mathrm{t}}$ dapat digunakan Persamaan (13).

$$
\left[\begin{array}{c}
V_{a n} \\
V_{b n} \\
V_{c n}
\end{array}\right]=\frac{V d c}{3}\left[\begin{array}{ccc}
2 & -1 & -1 \\
-1 & 2 & -1 \\
-1 & -1 & 2
\end{array}\right] \cdot\left[\begin{array}{l}
\mathrm{a} \\
\mathrm{b} \\
\mathrm{c}
\end{array}\right]
$$

Sehingga dapat dibuat tabel tegangan pada setiap vektornya yang ditunjukkan pada Tabel 1 . Adapun langkah-langkah dalam menyusun SVPWM sebagai berikut:

1. Membuat sumber tiga fasa yang bisa diatur baik frekuensi dan tegangannya oleh sinyal kontrol.

2. Mengubah sinyal tiga fasa $V a b c$ menjadi $V_{\alpha}, V_{\beta}$ dan mencari sudut fasa $(\alpha)$

3. Menentukan lamanya waktu switching $\mathrm{T}_{1}, \mathrm{~T}_{2}$ dan $\mathrm{T}_{0}$

4. Menentukan lamanya waktu switching tiap transistor $\left(\mathrm{S}_{1}\right.$ sampai $\left.\mathrm{S}_{6}\right)$

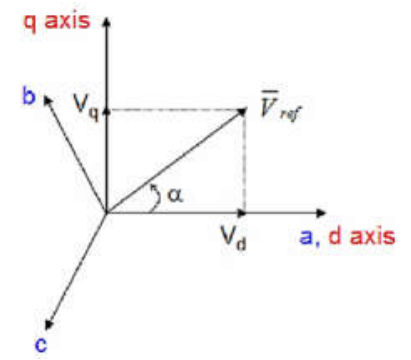

Gambar 5. Posisi $\alpha$ dan Vref dalam sumbu dq

Membuat sumber tiga fasa dengan beda fasa $120^{\circ}$. Membuat fungsi sinus kemudian menggesernya dengan $-2 \pi / 3$ dan $2 \pi / 3$. Penentuan tegangan $V_{\alpha}, V_{\beta}$ dan sudut $\alpha$ menggunakan transformasi Clarke yang ditunjukkan pada
Persamaan (14). Posisi a referensi dua fasa ditunjukkan pada Gambar 5.

$$
\left[\begin{array}{l}
V_{\alpha} \\
V_{\beta}
\end{array}\right]=\frac{2}{3} \cdot\left[\begin{array}{ccc}
1 & -\frac{1}{2} & -\frac{1}{2} \\
0 & \frac{\sqrt{3}}{2} & -\frac{\sqrt{3}}{2}
\end{array}\right] \cdot\left[\begin{array}{l}
V_{a n} \\
V_{b n} \\
V_{c n}
\end{array}\right]
$$

Sedangkan untuk mencari tegangan $\mathrm{V}_{\text {ref }}$ dan $\alpha$ dapat ditentukan jika diketahui nilai $\mathrm{V}_{\alpha}$ dan $\mathrm{V}_{\beta}$ yang ditunjukkan pada Persamaan (15) dan (16).

$$
\begin{aligned}
& \left|\bar{V}_{\text {ref }}\right|=\sqrt{V_{\alpha}^{2}+} V_{\beta}^{2} \\
& \alpha=\tan ^{-1}\left(\frac{V_{\beta}}{V_{\alpha}}\right)=\omega t=2 \pi f t
\end{aligned}
$$

Menentukan lamanya waktu switching $\mathrm{T}_{1}, \mathrm{~T}_{2}$ dan $\mathrm{T}_{0}$ pada tiap sektornya ditunjukkan Persamaan (17) yang mengacu pada Gambar 5.

$$
\begin{aligned}
& T_{1}=\frac{\sqrt{3} \cdot T_{Z} \cdot V_{\text {ref }}}{V_{d c}}\left(\sin \frac{n}{3} \cdot \cos \alpha-\cos \frac{n}{3} \cdot \sin \alpha\right) \\
& T_{2}=\frac{\sqrt{3} \cdot T_{Z} \cdot V_{\text {ref }}}{V_{d c}}\left(-\cos \alpha \cdot \sin \frac{(n-1) \pi}{3}+\sin \alpha \cdot \cos \frac{(n-1) \pi}{3}\right) \\
& T_{0}=T_{Z}-T_{1}-T_{2}
\end{aligned}
$$

dimana, $\mathrm{n}$ adalah urutan sektor $(\mathrm{n}=1,2, \ldots, 6)$

Menentukan lamanya waktu switching tiap transistor pada tiap sektor menggunakan pola pada Tabel 2.

Tabel 2. Lama waktu pensaklaran $\mathrm{S}_{1}$ sampai $\mathrm{S}_{6}$

\begin{tabular}{|c|l|l|}
\hline Sector & Upper Switches $\left(S_{1}, S_{3}, S_{5}\right)$ & Lower Switches $\left(S_{4}, S_{6}, S_{2}\right)$ \\
\hline \multirow{3}{*}{1} & $S_{1}=T_{1}+T_{2}+T_{0} / 2$ & $S_{4}=T_{0} / 2$ \\
& $S_{3}=T_{2}+T_{0} / 2$ & $S_{6}=T_{1}+T_{0} / 2$ \\
& $S_{5}=T_{0} / 2$ & $S_{2}=T_{1}+T_{2}+T_{0} / 2$ \\
\hline \multirow{3}{*}{2} & $S_{1}=T_{1}+T_{0} / 2$ & $S_{4}=T_{2}+T_{0} / 2$ \\
& $S_{3}=T_{1}+T_{2}+T_{0} / 2$ & $S_{6}=T_{0} / 2$ \\
& $S_{5}=T_{0} / 2$ & $S_{2}=T_{1}+T_{2}+T_{0} / 2$ \\
\hline \multirow{3}{*}{3} & $S_{1}=T_{0} / 2$ & $S_{4}=T_{1}+T_{2}+T_{0} / 2$ \\
& $S_{3}=T_{1}+T_{2}+T_{0} / 2$ & $S_{6}=T_{0} / 2$ \\
& $S_{5}=T_{2}+T_{0} / 2$ & $S_{2}=T_{1}+T_{0} / 2$ \\
\hline \multirow{3}{*}{4} & $S_{1}=T_{0} / 2$ & $S_{4}=T_{1}+T_{2}+T_{0} / 2$ \\
& $S_{3}=T_{1}+T_{0} / 2$ & $S_{6}=T_{2}+T_{0} / 2$ \\
& $S_{5}=T_{1}+T_{2}+T_{0} / 2$ & $S_{2}=T_{0} / 2$ \\
\hline \multirow{3}{*}{5} & $S_{1}=T_{2}+T_{0} / 2$ & $S_{4}=T_{1}+T_{0} / 2$ \\
& $S_{3}=T_{0} / 2$ & $S_{6}=T_{1}+T_{2}+T_{0} / 2$ \\
& $S_{5}=T_{1}+T_{2}+T_{0} / 2$ & $S_{2}=T_{0} / 2$ \\
\hline \multirow{2}{*}{6} & $S_{1}=T_{1}+T_{2}+T_{0} / 2$ & $S_{4}=T_{0} / 2$ \\
& $S_{3}=T_{0} / 2$ & $S_{6}=T_{1}+T_{2}+T_{0} / 2$ \\
& $S_{5}=T_{1}+T_{0} / 2$ & $S_{2}=T_{2}+T_{0} / 2$ \\
\hline
\end{tabular}

\section{PERANCANGAN SISTEM}

Pada bagian ini dirancang sistem pengaturan kecepatan motor induksi tiga fasa. Terdiri dari beberapa tahapan yaitu tahapan simulasi adalah 
dengan membuat model matematis motor induksi tiga fasa, perancangan switching SVPWM dan perancangan kontroler. Diagram blok sistem secara keseluruhan ditunjukkan pada Gambar 6 .

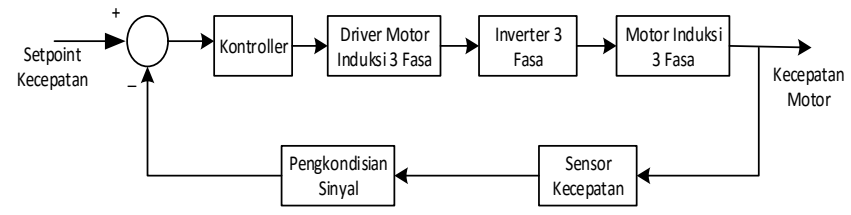

Gambar 6. Diagram blok sistem

\section{HASIL PENELITIAN DAN PEMBAHASAN}

Motor induksi yang digunakan adalah motor induksi jenis rotor sangkar (squirrel-cage) hubungan bintang. Keluaran yang dihasilkan dari motor induski tiga fasa ini terdiri dari sistem elektrik adalah nilai fluks stator dan torsi elektromagnetik sedangkan sistem mekanisnya adalah kecepatan putaran rotor. Parameter motor induksi yang digunakan mempunyai parameter ditunjukkan pada Tabel 3.

Dengan memasukkan parameter motor induksi ke dalam Persamaan (5) maka didapatkan parameter arus dalam sumbu d-q seperti pada Persamaan (16).

Tabel 3. Parameter Motor Induksi Tiga Fasa

\begin{tabular}{|l|c|c|}
\hline \multicolumn{1}{|c|}{ Nama } & Simbol & Nilai \\
\hline Resistansi stator $(\mathrm{W})$ & $\mathrm{Rs}$ & 0,435 \\
\hline Induktansi stator $(\mathrm{H})$ & $\mathrm{Lls}$ & 0,002 \\
\hline Resistansi rotor $(\mathrm{W})$ & $\mathrm{Rr}$ & 0,186 \\
\hline Induktansi rotor $(\mathrm{H})$ & $\mathrm{Llr}$ & 0,002 \\
\hline Mutual induktansi (H) & $\mathrm{M}$ & 0,069 \\
\hline Momen Inersia $\left(\mathrm{kgm}^{2}\right)$ & $\mathrm{J}$ & 0,089 \\
\hline Konstanta Gesek $\left(\mathrm{kg} \cdot \mathrm{m}^{2} / \mathrm{s}\right)$ & $\mathrm{B}$ & 0,005 \\
\hline Kutub & $\mathrm{P}$ & 2 \\
\hline
\end{tabular}

Arus dalam sumbu d-q digunakan untuk menentukan torsi elektromagnetik (Te) yang dihasilkan oleh motor dengan menggunakan Persamaan (10).

$$
\begin{aligned}
\frac{d}{d t}\left[\begin{array}{l}
i_{d s} \\
i_{q s} \\
i_{d r} \\
i_{q r}
\end{array}\right]= & \frac{1}{0,0028}\left[\begin{array}{cccc}
-0,03 & \omega_{r} x 0,0047 & 0,012 & \omega_{r} x 0,049 \\
0,03 & -\omega_{r} x 0.0003 & -0,435 x 0,071 & \omega_{r} x 0,005 \\
-\omega_{r} x 0,047 & 0,030 & \omega_{r} x 0,0048 & 0,0128 \\
\omega_{r} x 0,0048 & 0,435 x 0,069 & \omega_{r} x 0,030 & -0,013
\end{array}\right] \times\left[\begin{array}{c}
i_{d s} \\
i_{q s} \\
i_{d r} \\
i_{q r}
\end{array}\right] \\
& +\frac{1}{0,0028}\left[\begin{array}{cccc}
0,071 & 0 & -0,069 & 0 \\
-0,069 & 0 & 0,071 & 0 \\
0 & 0,071 & 0 & -0,069 \\
0 & 0,069 & 0 & 0,071
\end{array}\right] \times\left[\begin{array}{c}
V_{d s} \\
V_{q s} \\
0 \\
0
\end{array}\right]
\end{aligned}
$$

Untuk mendapatkan kecepatan dalam satuan (rpm), maka keluaran harus dikalikan dengan 30/ $\pi$. Respon kecepatan motor induksi tanpa beban dengan frekuensi $50 \mathrm{~Hz}$ ditunjukkan pada Gambar 8, sedangkan torsi elektromagnetik yang dihasilkan oleh motor induksi dengan torsi ditunjukkan pada Gambar 9. Dimana torsi awal yang dihasilkan oleh motor induksi sangat besar sekitar $65 \mathrm{Nm}$ berlangsung selama $5 \mathrm{~ms}$. Ini terjadi karena saat start arus yang diperlukan motor induksi sangat besar.

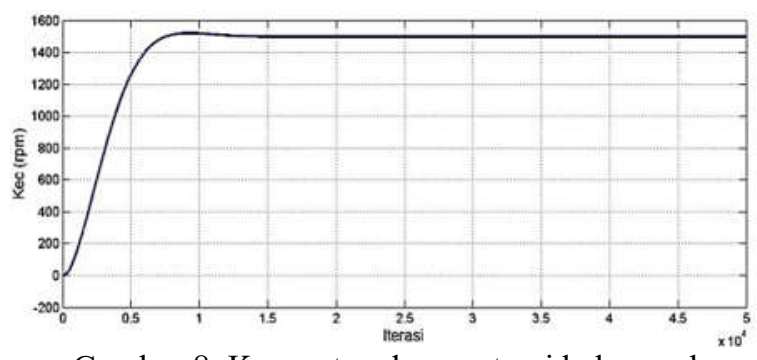

Gambar 8. Kecepatan dengan torsi beban nol

Kecepatan akan menurun jika terdapat torsi beban pada motor induksi hal ini sesuai dengan Persamaan (10). Pengaruh perubahan torsi beban (TL) terhadap kecepatan ditunjukkan pada Gambar 10.

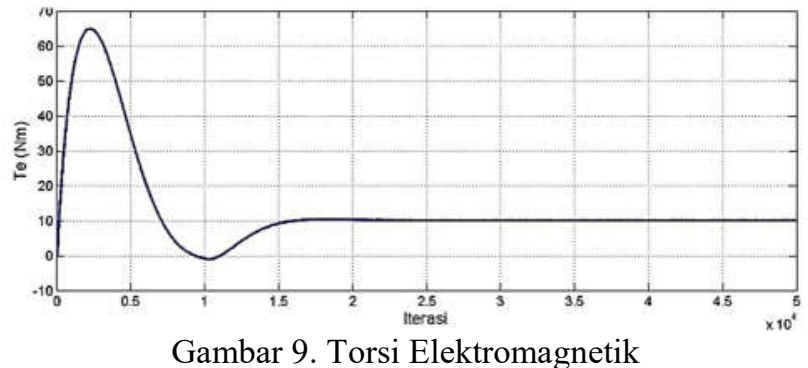

Terjadi penurunan kecepatan sebesar $400 \mathrm{rpm}$ pada saat diberikan torsi beban sebesar $20 \mathrm{Nm}$. Hal ini sangat mempengaruhi kinerja dari sistem. Jika model motor induksi sudah sesuai dengan yang 
Jurnal ECOTIPE, Volume 6, No.1, April 2019, Hal. 24-31

p-ISSN 2355-5068, e-ISSN 2622-4852

DOI: $10.33019 /$ ecotipe.v6i1.943

diharapkan langkah berikutnya adalah menyusun switching SVPWM untuk inverter.

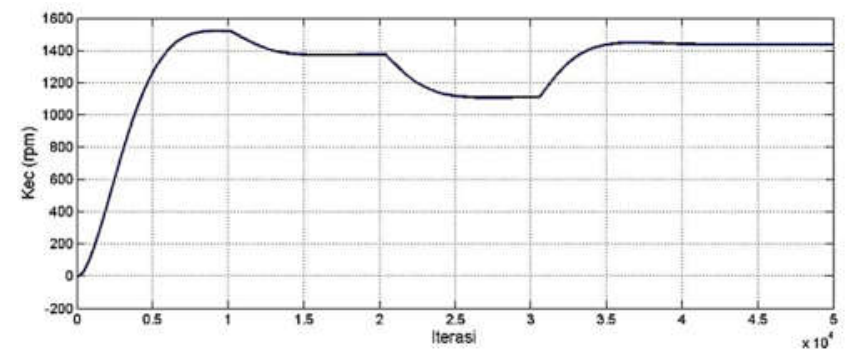

Gambar 10. Kecepatan dengan torsi beban 10,20,5 Nm

Blok diagram secara keseluruhan switching SVPWM ditunjukkan pada Gambar 11. Sinyal keluaran digunakan untuk mengatur frekuensi dan tegangan untuk membangkitkan sinyal sinus tiga fasa $(V a b c)$.

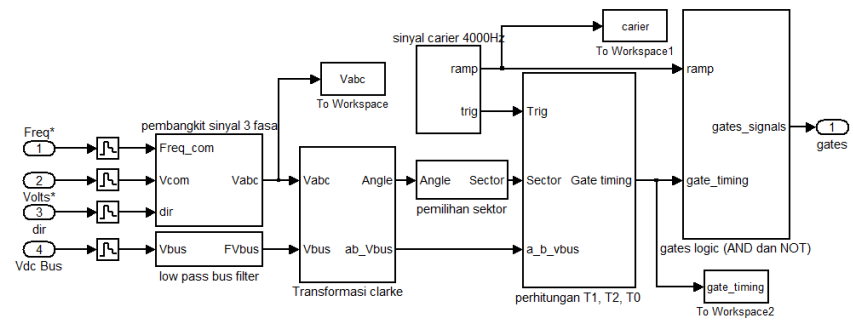

Gambar 11. Diagram Simulink SVPWM

Sinyal sinus tiga fasa diubah menjadi dua fasa $V \alpha$ dan $V \beta$ menggunakan transformasi Clarke pada Persamaan (14) kemudian dihitung sudut fasanya $(\alpha)$.

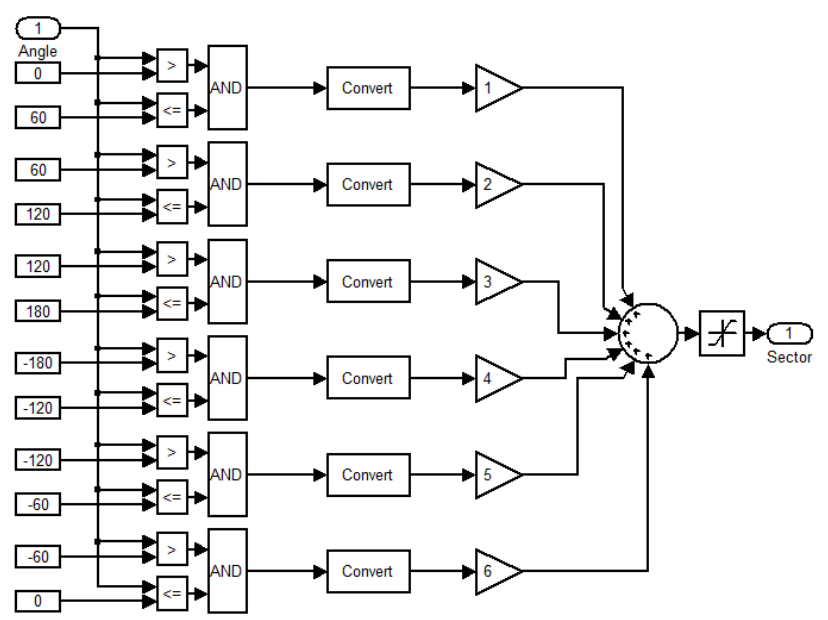

Gambar 12. Diagram simulink penentuan sektor

Diagram simulink untuk menentukan sektor yang aktif ditunjukkan pada Gambar 12. Sudut $\alpha$ digunakan menentukan sektor mana yang aktif.
Dari sektor yang aktif dapat ditentukan pola pensaklaran seperti pada Tabel 2. Diagram pewaktuan yang dihasilkan oleh $T_{1}, T_{2}$ dan $T_{0}$ untuk pemicu gate inverter ditunjukkan pada Gambar 13.

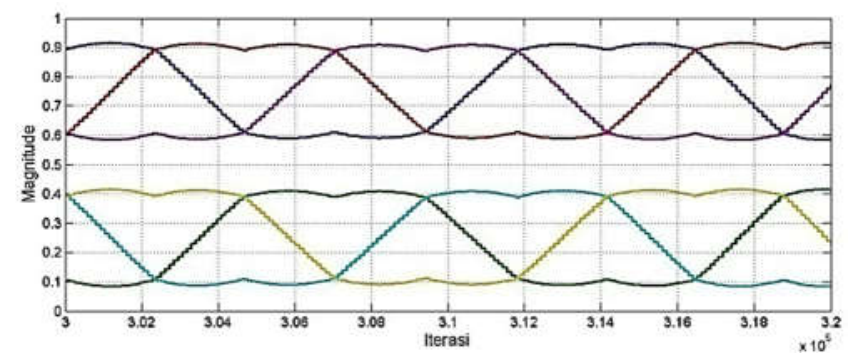

Gambar 13. Diagram pewaktu pemicu gate inverter

Tegangan yang diterima oleh motor induksi setelah melalui proses switching ditunjukkan pada Gambar 14. Tegangan tersebut adalah tegangan $V a b$. Tegangan $V a b$ adalah hasil modulasi sinyal pembawa $4000 \mathrm{~Hz}$ dengan sinyal gate timing.

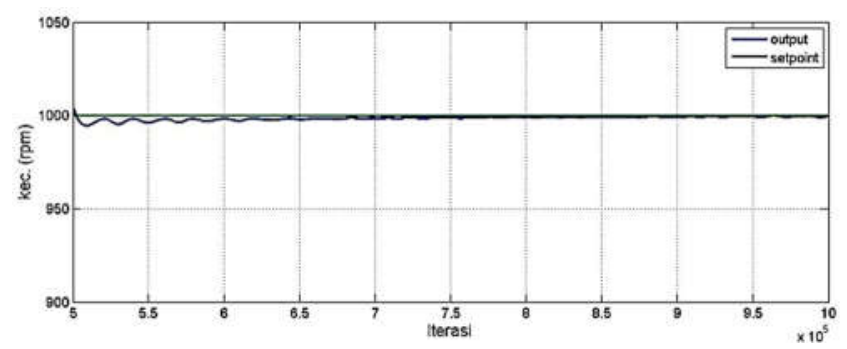

Gambar 14. Respon kecepatan sistem

Sedangkan torsi elektromagnetik yang dihasilkan masih berosilasi pada kondisi steady state. Respon torsi elektromagnetik yang dihasilkan oleh motor induksi ditunjukkan pada Gambar 15.

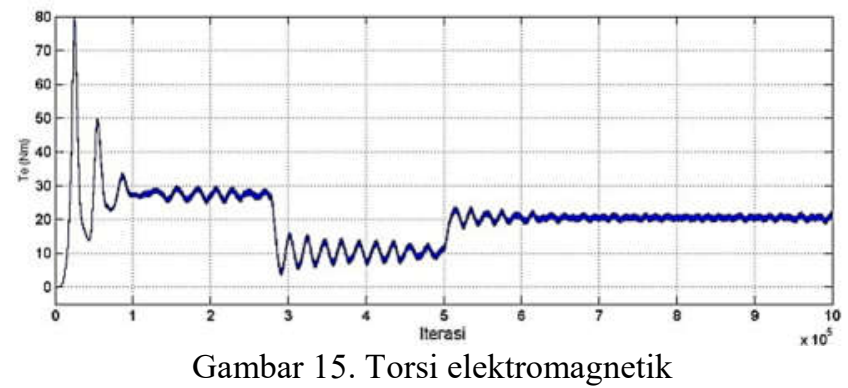

V. KESIMPULAN

Pada grafik respon diagram pewaktuan terlihat sinyal keluaran untuk diagram pewaktuan memiliki perbedaan pewaktuan sebesar $120^{\circ}$. Hal 
ini sudah sesuai dengan system 3 fasa dengan perbedaan antar fasa sebesar $120^{\circ}$ dan didapatkan nilai error steady state sebesar $0,2 \%$ atau dengan kesalahan tunak $2 \mathrm{rpm}$. Torsi elektromagnetik yang dihasilkan oleh motor induksi terdapat osilasi. Penelitian selanjutnya bisa diterapkan kombinasi antara switching SVPWM dengan DTC untuk mengatasi osilasi pada torsi elektromagnetik yang dihasilkan motor induksi tiga fasa.

\section{DAFTAR PUSTAKA}

[1] Dubey, G. K. (1989). Power Semiconductor Controlled Drives. Prentice-Hall International, New Jersey.

[2] Boldea ion, Nasar S. A. (1999). Electric Drives. CRC Press LLC.

[3] Purwanto, E. dan Ashary, M. (2008). Pengembangan inverter fuzzy logic kontrol untuk pengendalian motor induksi sebagai penggerak mobil listrik dengan metoda vektor control. Teknik Elektro, FTI ITS, Makara Teknologi.

[4] Kar, B. N. dan Mohanty, K. B. (2011). Indirect vektor kontrol of Induction Motor Using Fuzzy logic controller. Department of Electrical Engineering, National Institute of Technology, Rourkela, IEEE.

[5] R. Arulmozhiyal, R. dan Baskaran, K. (2009). Space Vector Pulse Width Modulation Based Speed Control of Induction Motor using Fuzzy PI Controller. IEEE International Journal of Computer and Electrical Engineering, Vol. 1, No. 1, April 2009.

[6] Lepka, J. dan Stekl, P. (2005). 3-Phase AC Induction Motor vector control Using a 56F80x, 56F8100 or $56 F 8300$ Device. Freescale Semiconductor.
[7] Anitha, P. dan Chowdhury, H. B. (2007). Sensorless control of inverter-fed induction motor drives. Electrical \& Computer Engineering Department, University of Missouri-Rolla, Electric Power Systems Research 77 Hal 619-629.

[8] Oguz, Y. dan Dede, M. (2010). Speed estimation of vector controlled squirrel cage asynchronous motor with artificial neural networks. Department of Electrical Education, Faculty of Technical Education, Afyon Kocatepe University, Afyonkarahisar, Turkey, Energy Conversion and Management 52 Hal 675-686. 